\title{
Comment
}

Cerebrovascular Diseases

Cerebrovasc Dis 2011;31:390-391

DOI: $10.1159 / 000323334$

\section{Effective Fever Control in Acute Stroke: Still Wanted!}

A. Meisel

Department of Neurology, Charité University Medicine Berlin, Berlin, Germany

Even in specialized stroke units, up to $85 \%$ of the patients have at least one relevant complication, such as fever, infections, venous thromboembolism, seizures or cardiac complication. Most complications arise as a direct consequence of ischemic brain lesion or indirectly through the ensuing neurological deficits. Unsurprisingly, most clinical data suggest that complications worsen the final outcome of stroke patients. They not only increase mortality but might also enhance neuronal damage as well as impede neurological recovery [1]. Among all complications, fever and infections are of particular importance [2-4]. Why? Firstly, they are the most common complications affecting up to two thirds of all stroke patients. Secondly, they are predictors of poor outcome independent of initial stroke severity. Thirdly, they often arise within the first hours and days after stroke onset and thus within a time window accessible for effective prevention. Fourthly, at least in part, fever is due to post-stroke infections and successful prevention of post-stroke infections might control fever. Fifthly, appropriate pharmacological measures such as antipyretics and antibiotics to combat fever as well as infections have been in clinical use for decades. Thus, effective prevention and treatment of both complications should be rather trouble free, and, as a consequence, we should be able to improve prognosis after stroke. In fact, clinical trials suggest that treatment of poststroke fever as well as prevention of infections is feasible. However, the effects of lowering body temperature or reducing the frequency of infections are rather small or contradictory [1, 3-5]. More importantly, convincing evidence that these strategies improve post-stroke outcome are lacking. This might have 2 different reasons: (1) our treatment strategies are insufficient, for example the reduction of body temperature in patients with fever is too low, or (2) complications have no additional damaging effect on ischemic brain tissue, for example complications like fever are markers but not causes of poor prognosis. At least for fever, the latter seems to be rather unlikely, since not only did most clinical studies identify fever as an independent predictor of poor outcome but furthermore, preclinical data demonstrated that rais- ing body temperature increases infarct volume [6]. In addition, hypothermia is a proven treatment strategy in global brain ischemia ameliorating outcome after resuscitation [7]. However, different cooling strategies in acute stroke failed to improve outcome. Yet, the reduction of body temperature in these trials was rather low $[1,5]$. Consequently, current guidelines do not provide specific recommendations for fever treatment. Thus, in practice, post-stroke complications like fever are treated following clinical traditions and personal experience rather than grounded on trial-based evidence.

Kallmünzer et al. [8] investigated the safety of an institutional 4-step protocol using pharmacological and physical interventions in order to enforce post-stroke fever control. When body temperature was $\geq 37.5^{\circ} \mathrm{C}$, treatment was started with $1 \mathrm{~g}$ paracetamol intravenously (level 1) and in case of nonresponse followed hourly by treatment with $1 \mathrm{~g}$ metamizole intravenously (level 2), calf packing (level 3) and finally intravenous infusion of $500 \mathrm{ml}$ of $4^{\circ} \mathrm{C}$ cold saline solution (level 4). Using this protocol, normothermia was achieved within $2 \mathrm{~h}$ in more than $90 \%$ of the patients and the mean duration of fever was $2 \mathrm{~h}$ within the first 4 days after stroke onset. This strategy is safe and seems to be effective in terms of controlling fever compared to a control population. However, this study has several methodological limitations preventing conclusions in terms of efficacy. Most importantly, this study is an observational study using a retrospective control group. In addition, patients in the study group were significantly more often treated with antibiotics compared to the control population. One half of the study patients received antibiotics for infection prevention, a treatment strategy which might, but does not necessarily, lower body temperature in stroke patients $[9,10]$.

Observational studies like that of Kallmünzer et al. [8] might stimulate further research in this field of high clinical significance for acute stroke care. More than 3 decades after Hindfelt's [11] recommendation 'that fever and subfebrility, irrespective of their genesis, should be intensely combated during the early stages of an ischaemic stroke' we need a proven treatment strategy for fever control. More importantly, we need an effective strategy not only to reduce body temperature but also to improve long-term outcome. New methodologies are available for investigating the effect of complex interventions such as escalation strategies combining pharmacological as well as physical interventions, within the setting of controlled trials, for example cluster trials. It is time for more large randomized controlled trials investigating novel approaches to tackle the relevant post-stroke complications more efficiently.

\section{KARGER}

Fax +41613061234 E-Mail karger@karger.ch www.karger.com
(C) 2011 S. Karger AG, Basel

$1015-9770 / 11 / 0314-0390 \$ 38.00 / 0$ 


\section{References}

1 Kumar S, Selim MH, Caplan LR: Medical complications after stroke. Lancet Neurol 2010;9:105-118.

-2 Greer DM, Funk SE, Reaven NL, Ouzounelli M, Uman GC: Impact of fever on outcome in patients with stroke and neurologic injury: a comprehensive meta-analysis. Stroke 2008;39:3029-3035.

3 Emsley HC, Hopkins SJ: Acute ischaemic stroke and infection: recent and emerging concepts. Lancet Neurol 2008;7:341-353.

4 van de Beek D, Wijdicks EF, Vermeij FH, de Haan RJ, Prins JM, Spanjaard L, Dippel DW, Nederkoorn PJ: Preventive antibiotics for infections in acute stroke: a systematic review and meta-analysis. Arch Neurol 2009;66:1076-1081.

$\checkmark 5$ den Hertog HM, van der Worp HB, van Gemert HM, Algra A, Kappelle LJ, van Gijn J, Koudstaal PJ, Dippel DW, PAIS Investigators: The Paracetamol (Acetaminophen) In Stroke (PAIS) trial: a multicentre, randomised, placebo-controlled, phase III trial. Lancet Neurol 2009;8: 434-440.

6 Kim Y, Busto R, Dietrich WD, Kraydieh S, Ginsberg MD: Delayed postischemic hyperthermia in awake rats worsens the histopathological outcome of transient focal cerebral ischemia. Stroke 1996;27:22742280

$\checkmark 7$ Peberdy MA, Callaway CW, Neumar RW, Geocadin RG, Zimmerman JL, Donnino M, Gabrielli A, Silvers SM, Zaritsky AL, Merchant R, Vanden Hoek TL, Kronick SL: Part 9: post-cardiac arrest care: 2010 American Heart Association Guidelines for Cardiopulmonary Resuscitation and Emergency Cardiovascular Care. Circulation 2010;122:S768-S786.
8 Kallmünzer B, Krause C, Pauli E, Beck A, Breuer L, Köhrmann M, Kollmar R: Standardized antipyretic treatment in stroke: a pilot study. Cerebrovasc Dis 2011;31:382-389.

-9 Harms H, Prass K, Meisel C, Klehmet J, Rogge W, Drenckhahn C, Göhler J, Bereswill S, Göbel U, Wernecke KD, Wolf T, Arnold G, Halle E, Volk HD, Dirnagl U, Meisel A: Preventive antibacterial therapy in acute ischemic stroke: a randomized controlled trial. PLoS One 2008; 3:e2158.

10 Schwarz S, Al-Shajlawi F, Sick C, Meairs S, Hennerici MG: Effects of prophylactic antibiotic therapy with mezlocillin plus sulbactam on the incidence and height of fever after severe acute ischemic stroke: the Mannheim infection in stroke study (MISS). Stroke 2008;39:12201227.

11 Hindfelt B: The prognostic significance of subfebrility and fever in ischaemic cerebral infarction. Acta Neurol Scand 1976;53:72-79.

Prof. Dr. med. Andreas Meisel

Department of Neurology

Center for Stroke Research Berlin CSB

NeuroCure Clinical Research Center NCRC

Charité Universitätsmedizin Berlin

Charitéplatz 1

DE-10117 Berlin (Germany)

Tel. +4930450 560026, Fax +4930450560942

E-Mail andreas.meisel@charite.de 